\title{
Pengaruh Penggunaan Petunjuk Praktikum IPA Berbasis Learning Cycle Terhadap Practical Skills Siswa Kelas IV Sekolah Dasar
}

\author{
Faizal Chan \\ Program Studi PGSD-FKIP Universitas Jambi \\ faizal.chan@unja.ac.id \\ Hendra Budiono \\ Program Studi PGSD-FKIP Universitas Jambi \\ hendra.budiono@unja.ac.id
}

\begin{abstract}
This study aims to determine whether there is an effect of the use of learning cycle-based science practicum instructions on the practical skills of fourth grade students of SDN 131 / IV in Jambi City. This research was carried out at SDN 131 / IV Jambi City with the research subjects were 13 grade students. This research is a quasi-experimental one group pretest posttest design. The results showed that the significance value of the pretest and posttest was - 7.610 small from the alpha value of 0.05 (-7.610 $<0.05)$ which means that there is a significant influence between the use of learning cycle-based science practicum instructions on the practical skills of grade IV elementary schools. It can be concluded that there is a significant influence between the use of learning cycle-based science practicum instructions on the practical skills of class IV SDN 131 / IV Jambi City.
\end{abstract}

Keywords: practical instructions, learning cycle, practical skills

\section{Pendahuluan}

Pada tingkat sekolah dasar, pembelajaran IPA dipelajari untuk mencari tahu fenomena alam yang dilakukan secara ilmiah sebagai pengetahuan dasar sains. IPA sebagai komponen kurikulum mencakup pengetahuan yang lebih sistematis dan teratur berdasarkan data obeservasi maupun kegiatan eksperimen. Faizal dan Budiono (2019:1) menjelaskan bahwa pada dasarnya konsep IPA lebih kepada mencari tahu berbagai fenomena yang dilakukan secara ilmiah yang membentuk pemahaman konsep sampai pada penemuan fakta dari penemuan yang didapatkan.

Dalam prosesnya, IPA di SD menekankan pada pemberian pengalaman secara langsung untuk mengembangkan mencapai kompetensi yang dituntut dalam kurikulum. Untuk mecapai kompetensi tersebut pembelajaran IPA membutuhkan kegiatan praktikum sebagai bentuk integral dari pembelajaran IPA yang memberikan pengalaman langsung. Nisa (2017:63) menyatakan bahwa salah satu mata pelajaran yang membutuhkan pembelajaran secara langsung adalah mata pelajaran Ilmu Pengetahuan Alam (IPA) yang termuat dalam mata pelajaran tematik. IPA bukan hanya sekedar pelajaran yang di dalamnya berisi tentang penguasaan konsep, prinsip, atau penguasaan kumpulan pengetahuan berupa faktafakta, di dalam IPA dikenal dengan suatu proses penemuan. Dalam kegiatan pembelajaran IPA, praktikum adalah kegiatan yang bertujuan untuk membekali siswa agar lebih dapat memahami teori dan praktik. 
Margunayasa (2014) menjelaskan bahwa sebagai suatu yang tidak terpisahkan adanya kegiatan praktikum akan memberikan kesempatan kepada siswa dalam pengujian hipotesis melalui observasi objek yang nyata sebagai pembuktian konsep maupun teori yang dipelajari. Sumiati dan Asra (2009: 104) menyatakan bahwa latihan dan praktik mampu meningkatkan kemampuan maupun hasil belajar siswa dengan melakukan berbagai kegiatan situasi nyata siswa sehingga membawa siswa pada keadaan sebenarnya sehingga kegiatan memberikan pengalaman langsung. Dari definisi ini dapat diartikan bahwa capaian pembelajaran yang menjadi tujuan pembelajaran akan lebih mudah dicapai jika kegiatan pembelajaran menyajikan sesuatu yang sifatnya langsung seperti halnya praktikum. Sependapat dengan hal ini. Abdullah dan Marvira (2014: 25) menguraikan bahwa praktikum memberikan semangat dan minat siswa karena dalam pelaksanaannya siswa ikut berperan serta. Nisa (2017:67) menjelaskan bahwa pembelajaran dengan metode praktikum dapat meningkatkan pemahaman dan hasil belajar siswa menjadi baik.

Namun kenyataannya kegiatan praktikum di sekolah dasar masih jarang dilakukan. Windyariani (2017:27), yang menyatakan bahwa praktikum masih jarang dilakukan oleh para guru. Hak ini didukung hasil penelitiam yang menunjukkan sebanyak 75\% guru menyatakan bahwa guru merasa kesulitan dalam melaksanakan praktikum. Salah satu faktor penyebabnya adalah tidak tersedianya petunjuk praktikum yang dapat dijadikan acuan. Faizal dan Budiono (2019) menyatakan bahwa dibutuhkan panduan praktikum sehingga dalam mencapai pembelajaran dapat meningkatkan kemampuan kinerja. Kemampuan ini tentu bersifat ilmiah serta adanya pembentukan sikap yang lebih baik. Adanya petunjuk praktikum menjadikan kegiatan praktikum lebih terarah dan lebih terstruktur. Syamsu (2017:14) mengungkapkan bahwa keteraturan siswa dalam proses praktikum akan lebih terarah dengan adanya pedoman praktikum. Hal ini akan membantu guru dalam mengkondisikan kesiapan siswa ketika mulai melaksanakan praktikum.

Practical skills menjadi salah satu keterampilan yang dapat dikuasi oleh siswa sekolah dasar, seperti memilih alat dan bahan, pelaksanaan praktikum yang sistematis, keterampilan mengunakan perhitungan waktu atau memprediksi, serta keterampilan dalam mencatat hasil kegiatan. Handayani (2016) menyatakan bahwa berbagai kategori dalam practical skills merupakan bagian dalam prkatikum yang lebih menonjolkan keterampilan siswa. Penelitian Odo, dkk (2012) menunjukan salah satu aspek dalam proses pendidikan yang masih rendah adalah practical skills atau keterampilan praktis sehingga berkaitan dengan berbagai sektor kehidupan sosial.

Praktikum akan terlaksana sesuai dengan tujuan dan akan menemukan konsep yang sesuai jika dilengkapi dengan petunjuk praktikum. Diantaranya petunjuk praktikum berbasis learning cycle. Petunjuk praktikum IPA berbasis Learning Cycle dapat mengarahkan siswa dalam penemuan secara terstruktur sesuai dengan langkah-langkah atau tahapan yang lebih efektif dan efisisen. Hasil penelitian Faizal dan Budiono (2019) menunjukkan bahwa pada uji coba kelompok besar, kepraktisan mencapai 78, 75\% dengan kategori praktis. Hasil penelitian Qarareh (2012) menunjukkan bahwa struktur learning cycle akan memberikan proses kognitif yang aktif, berpusat pada siswa dan memberikan pengalaman pendidikan dan pengalaman secara eksploratif sehingga memungkinkan siswa untuk dapat menggali pengetahuannya.

Penelitian sebelumnya dilakukan oleh Handayani (2016), hasil penelitian ini menunjukan adanya peningkatan practical skills dengan menggunakan petunjuk praktikum IPA pada siswa SMP. Dari penelitian ini dapat dilihat bahwa adanya peningkatan practical skills siswa dengan menggunakan petunjuk praktikum. Perbedaan yang mendasar dengan penelitian yang akan dilakukan adalah penilitian 
ini dilakukan utuk melihat sebeberapa besar pengaruh penggunaan petunjuk praktikum IPA berbasis learning cycle terhadap practical skills siswa. Penelitian ini bertujuan untuk mengetahui ada tidaknya pengaruh-pengaruh penggunaan petunjuk praktikum IPA berbasis learning cycle terhadap practical skills siswa kelas IV SDN 131/IV Kota Jambi.

\section{Metode}

Penelitian ini menggunakan pendekatan kuantitatif dengan jenis quasi eksperiment one group pretest posttest design. Untuk mengetahuai adanya perubahan variabel dependen maka dilakukan tes awal dan tes akhir yang sebelumnya diterapakan penggunaan petunjuk praktikum IPA berbasis learning cycle.

Populasi dalam penelitian ini adalah siswa kelas IV dengan sampel penelitian adalah siswa shif pagi kelas IV SDN 131/IV Kota Jambi Tahun ajaran 2019/2020 yang berjumlah 13 orang yang dipilih secara random sampling. Pemilihan lokasi SDN 131/IV Kota Jambi dikarenakan SD ini merupakan mitra prodi PGSD Universitas Jambi sehingga diketahui kualitas pembelajaran IPA perlu ditingkatkan khususnya pada aspek praktical skill.

Instrumen yang digunakan untuk melihat pengaruh penggunaan petunjuk praktikum IPA berbasis learning cycle terhadap practical skills siswa kelas IV SDN 131/IV Kota Jambi berupa lembar observasi pretest dan posttest.

Pengumpulan data dalam penelitain ini berupa observasi practical skills siswa selama proses kegiatan praktkum dilakukan. Hasil observasi digunakan untuk mengukur tingkat practical skills siswa saat pretest dan posttest. Pengumpulan data pretest untuk mengatahui kondisis kelompok eksperimen sebelum diberikan perlakuan. Selanjutnya perlakuan (X) yang akan diberikan terhadap kelompok eksperimen, diharapkan akan dapat menunjukkan pengaruh penggunaan petunjuk praktikum IPA berbasis learning cycle terhadap practical skills siswa kelas IV SDN 131/IV Kota Jambi.

Teknik analisis data dilakukan dengan $N$-Gain atau normalisasi gain. $N$-Gain dalam hal ini untuk menghindari bias dari penelitian yang didapat dari perbedaan hasil pretest dan postest. Gain merupakan selisih nilai antara posttest dan pretest. Dengan adanya $N$-Gain akan tampak tingkat keberhasilan sebelum dan setelah diberikan perlakuan. Nilai $N$-Gain nantinya juga digunakan untuk analisis data mencakup uji hipotesis pada penelitian.

Pada pengujian hipotesis dari penelitian, akan dilakukan secara nonparametrik dengan uji Wilcoxon untuk sampel kecil dan perhitungan juga dengan menggunakan bantuan SPSS for windows release 20.00. $\mathrm{H}_{0}$ : Tidak terdapat pengaruh signifikan antara penggunaan petunjuk praktikum IPA berbasis learning cycle terhadap practical skills kelas IV SDN 131/IV Kota Jambi. Ha: Terdapat pengaruh signifikan antara penggunaan petunjuk praktikum IPA berbasis learning cycle terhadap practical skills kelas IV IV SDN 131/IV Kota Jambi.

Uji hipotesis melibatkan perhitugan data pretest dan posttest. Dalam pengambilan uji hipotesis, hipotesis diterima apabila nilai $t_{\text {hitung }} \leq \mathrm{t}_{\text {tabel. }}$. Maka terdapat pengaruh antara variabel $x$ dan varibel y. Sedangkan apabila nilai thitung $\geq t_{\text {tabel. }}$ Maka tidak terdapat pengaruh antara variabel $\mathrm{x}$ dan variabel $\mathrm{y}$ atau hipotesis ditolak. 


\section{Hasil}

Penelitian ini dilaksanakan pada bulan Maret sampai dengan bulan Juli 2020. Pelaksanaan pengambilan data dilakukan di kelas IV SDN 131/IV Kota Jambi pada tanggal 16 Juli 2020. Kegiatan ini dilaksanakan pada masa uji coba dimulainya sekolah di Kota Jambi secara tatap muka bagi siswa kelas tinggi. Subjek penelitian ini adalah siswa kelas IV yang masuk pada shif pagi dengan jumlah 13 orang. Secara spesifik penelitian ini untuk mengetahui pengaruh penggunaan petunjuk praktikum IPA berbasis learning cycle terhadap practical skills siswa kelas IV SDN 131/IV Kota Jambi. Data-data diperoleh merupakan hasil prestest dan Postest berkaitan dengan practical skills siswa.

Berdasarkan data yang diperoleh, dapat dideskripsikan hasil penelitian sebelum diberikan perlakuan (pretest) dan sudah diberikan perlakuan (postest) yang diolah dengan menggunakan SPSS versi 20.00 for windows sebagai berikut.

Tingkat practical skills siswa kelas IV SDN 131/IV Kota Jambi sebelum perlakukan (Pretest)

Data Pretest siswa berkaitan dengan tingkat practical skills dalam kegiatan praktikum dapat dilihat pada tabel 1 .

Tabel 1. Hasil pretest kelompok eksperimen tentang practical skills siswa kelas IV

\begin{tabular}{cccc}
\hline \multirow{2}{*}{ No. } & Inisial Siswa & \multicolumn{2}{c}{ Pretest } \\
\cline { 3 - 4 } & & Skor & Kategori \\
\hline 1 & LS & 67,86 & Tinggi \\
\hline 2 & ES & 39,29 & Sangat Rendah \\
\hline 3 & RK & 71,43 & Tinggi \\
\hline 4 & DF & 60,71 & Sedang \\
\hline 5 & RA & 71,43 & Tinggi \\
\hline 6 & TF & 67,86 & Tinggi \\
\hline 7 & SY & 75,00 & Tinggi \\
\hline 8 & CD & 67,86 & Tinggi \\
\hline 9 & YL & 85,71 & Sangat Tinggi \\
\hline 10 & CL & 39,29 & Sangat Rendah \\
\hline 11 & ZN & 46,43 & Rendah \\
\hline 12 & TR & 60,71 & Tedang \\
\hline 13 & VR & 67,86 & Tinggi \\
\hline
\end{tabular}

Tabel 1 menunjukkan kondisi practical skills 13 siswa kela IVA SDN 131/IV Kota Jambi dengan kondisi kemampuan practical skills kategoi sangat rendah yaitu ES dan CL dengan skor masing-masing 39,29. Kemampuan practical skills dengan kategori rendah ZN dengan skor 46,43. Kategori sedang yakni DF dan TR dengan skor masing-masing 60,71. Kategori tinggi LS dengan Skor 67,86, RK dengan skor 71,43, RA dengan skor 71,43, TF dengan skor 67,86, SY dnegan skor 75, CD dengan skor 67,86 dan VR dengan skor 67,86. Sementara itu untuk kategori sangat tinggi diperoleh 1 orang siswa yakni YL dengan skor 85,71.

Tingkat practical skills siswa kelas IV SDN 131/IV Kota Jambi setelah perlakukan (Postest)

Data postest tingkat practical skills siswa kelas IV SDN 131/IV Kota Jambi dapat dilihat pada tabel 2 berikut. 
Tabel 2. Hasil pretest kelompok eksperimen tentang Hasil Pretest practical skills siswa kelas IV

\begin{tabular}{cccc}
\hline \multirow{2}{*}{ No. } & Inisial Siswa & Skor & Postest \\
\cline { 3 - 4 } & & 89,29 & Kategori \\
\hline 1 & LS & 42,86 & Sangat Tinggi \\
\hline 2 & ES & 100 & Sendah \\
\hline 3 & RK & 89,29 & Sangat Tinggi \\
\hline 4 & DF & 89,29 & Sangat Tinggi \\
\hline 5 & RA & 82,14 & Sangat Tinggi \\
\hline 6 & TF & 96,43 & Sangat Tinggi \\
\hline 7 & SY & 100 & Sangat Tinggi \\
\hline 8 & CD & 100 & Sangat Tinggi \\
\hline 9 & YL & 85,71 & Sangat Tinggi \\
\hline 10 & CL & 89,29 & Sangat Tinggi \\
\hline 11 & ZN & 92,86 & Sangat Tinggi \\
\hline 12 & TR & 89,29 & Sangat Tinggi \\
\hline 13 & VR & &
\end{tabular}

Berdasarkan tabel 2 dapat dimaknai bahwa dari 13 siswa yang menjadi subjek penelitian dapat didapat 1 siswa dengan kategori rendah dengan skor 42,86, dan 12 lainnya dengan kategori sangat tinggi.

Perbedaan Hasil Pretest dan Postest Kemampuan Practical Skills siswa kelas IV SDN $131 /$ IV Kota Jambi

Hasil pretest dan postest yang sudah dilakukan, dapat dilihat perbedaan tingkat kemampuan Practical Skills siswa sebagai berikut

Tabel 3. Perbedaan Hasil Pretest dan Postest Kelompok Eksperimen tentang Practical Skills Siswa Kelas IV SDN 131/IV Kota Jambi

\begin{tabular}{cccccc}
\hline \multirow{2}{*}{ No. } & Inisial & \multicolumn{2}{c}{ Pretest } & \multicolumn{2}{c}{ Postest } \\
\cline { 3 - 6 } & Siswa & Skor & Kategori & Skor & Kategori \\
\hline 1 & LS & 67,86 & Tinggi & 89,29 & Sangat Tinggi \\
\hline 2 & ES & 39,29 & Sangat Rendah & 42,86 & Rendah \\
\hline 3 & RK & 71,43 & Tinggi & 100 & Sangat Tinggi \\
\hline 4 & DF & 60,71 & Sedang & 89,29 & Sangat Tinggi \\
\hline 5 & RA & 71,43 & Tinggi & 89,29 & Sangat Tinggi \\
\hline 6 & TF & 67,86 & Tinggi & 82,14 & Sangat Tinggi \\
\hline 7 & SY & 75,00 & Tinggi & 96,43 & Sangat Tinggi \\
\hline 8 & CD & 67,86 & Tinggi & 100 & Sangat Tinggi \\
\hline 9 & YL & 85,71 & Sangat Tinggi & 100 & Sangat Tinggi \\
\hline 10 & CL & 39,29 & Sangat Rendah & 85,71 & Sangat Tinggi \\
\hline 11 & ZN & 46,43 & Rendah & 89,29 & Sangat Tinggi \\
\hline 12 & TR & 60,71 & Sedang & 92,86 & Sangat Tinggi \\
\hline 13 & VR & 67,86 & Tinggi & 89,29 & Sangat Tinggi \\
\hline Skor Total & 821,44 & & 1146,45 & \\
\hline Rata-rata & 63,19 & Sedang & 88,19 & Sangat Tinggi \\
\hline
\end{tabular}

Skor pada tabel 3 menunjukkan bahwa adanya peningkatan kemampuan practical skills menggunakan petunjuk praktikum IPA Berbasis Learning Cycle. Artinya hasil ini menujukkan suatu keadaan kemampuan practical skills yang sangat baik. Perbedaa frekuensi masing-masing kategori dapat dilihat pada tabel 4 . 
Untuk melihat perbedaan frekuensi kondisi kemampuan practical skills masingmasing kategori dari hasil pretest dan postest dijabarkan pada tabel 4 berikut.

Tabel 4. Distribusi frekuensi skor Pretest dan Postest Kelompok Eksperimen Tentang Practical Skills Siswa Kelas IV SDN 131/IV Kota Jambi

\begin{tabular}{cccccc}
\hline \multirow{2}{*}{ No. } & \multirow{2}{*}{ Kategori } & \multicolumn{2}{c}{ Pretest } & \multicolumn{2}{c}{ Postest } \\
\cline { 3 - 6 } & & $\mathbf{F}$ & $\mathbf{\%}$ & $\mathbf{F}$ & $\mathbf{\%}$ \\
\hline $80-100$ & Sangat Tinggi & 1 & 7,69 & 12 & 92,31 \\
\hline $66-79$ & Tinggi & 7 & 53,86 & 0 & 0 \\
\hline $56-65$ & Sedang & 2 & 15,38 & 0 & 0 \\
\hline $40-55$ & Rendah & 1 & 7,69 & 1 & 7,69 \\
\hline $30-39$ & Sangat Rendah & 2 & 15,38 & 0 & 0 \\
\hline Skor Total & & $\mathbf{1 3}$ & $\mathbf{1 0 0}$ & $\mathbf{1 3}$ & $\mathbf{1 0 0}$ \\
\hline
\end{tabular}

Tabel 5. Gambaran perbedaan hasil skor Pretest dan Postest Kelompok Eksperimen Tentang Practical Skills Siswa Kelas IV SDN 131/IV Kota Jambi Mean N Std. Deviation Minimum Maximum

\begin{tabular}{cccccc}
\hline Pretest & 17,69 & 13 & 3,881 & 39,29 & 85,71 \\
\hline Postest & 24,69 & 13 & 4,131 & 42,86 & 100
\end{tabular}

Hipotesis penelitian tentang Pengaruh Penggunaan Petunjuk Praktikum IPA Berbasis Learning Cycle Terhadap Practical Skills Siswa Kelas IV SDN 131/IV Kota Jambi sebagai berikut.

$\mathrm{H}_{\mathrm{o}} \mathrm{p}=0$ : Tidak terdapat pengaruh signifikan antara penggunaan petunjuk praktikum IPA berbasis learning cycle terhadap practical skills kelas IV SDN 131/IV Kota Jambi.

Ha $: p \neq 0$ : Terdapat pengaruh signifikan antara penggunaan petunjuk praktikum IPA berbasis learning cycle terhadap practical skills kelas IV SDN 131/IV Kota Jambi.

Hipotesis akan dianalisis melalui statistik nonparametrik dengan uji wilcoxon's, menggunakan SPSS for windows 20.00. Pengujian hipotesis dengan uji wilxocon's dapat dilihat pada tabel berikut ini.

Tabel 6. Hasil Wilcoxons Signed Rank Test Pretest-Postest Kelompok Eksperimen Tentang Practical Skills Siswa Kelas IV SDN 131/IV Kota Jambi Pretest dan Postest

\begin{tabular}{cc}
\multicolumn{3}{c}{ Pretest dan Postest } \\
\hline S & $-7,610$ \\
\hline Sig. (2-tailed) &, 005 \\
\hline
\end{tabular}

a. Wilcoxon Signed Ranks Test

b. Based on positive ranks.

Nilai signifikansi pretest dan Postest sebesar -7,610 kecil dari nilai alpha 0,05 (-7,610 $<0,05)$ dapat di artikan Ho ditolak dan Ha diterima, diperoleh kesimpulan bahwa terdapat pengaruh signifikan antara penggunaan petunjuk praktikum IPA berbasis learning cycle terhadap practical skills kelas IV Sekolah Dasar.

\section{Pembahasan}

\section{Kondisi Kemampuan Practical Skills Siswa Sebelum diberikan Perlakuan (pretest).}

Kondisi kemampuan practical skills Siswa ketika proses pembelajaran IPA dilakukan di kelas IV menunjukkan 63,19 dengan kategori sedang. Selama proses pembelajaran dapat diamati bahwa dalam prose pembelajaran belum 
memperlihatkan kemampuan practikal skills yang diharapkan dapat terintegrasi pada diri siswa melalui pembelajaran IPA.

Kemampuan practical skills siswa yang berada pada kategori sedang dikarenakan proses pembelajaran yang masih terfokus pada buku guru dan buku siswa, tanpa adanya kegiatan praktikum yang dapat mengarahkan siswa menemukan konsep IPA sendiri serta pengetahuan dan keterampilan anak dapat berkembang. Astutik (2012:145) menjelaskan sebagai satu mata pelajaran di SD muatan IPA atau Sains mampu mengembangkan kemampuan berpikir siswa salah satunya adalah kemampuan berpikir analitis. Kemampuan ini dapat diperoleh dengan adanya penyelesaian masalah melalui berbagai peristiwa baik diselesaikan secara kualitatif maupun kuantitatif dengan harapan terbentuk pengetahuan, meningkatkanya keterampilan, serta tumbuhnya rasa percaya diri siswa.

Kegiatan pembelajaran yang kurang memfasilitasi siswa secara umum akan menghambat pengetahuan siswa, selain itu kegiatan pembelajaran yang hanya terpaku pada teks tidak akan menciptakan pembelajaran yang kondusif serta tidak dapat mengarahkan siswa menemukan konsep sebenarnya yang sangat perlu dimiliki siswa khususnya sekolah dasar. Afriyanti dan Sumardi (2017:6) menjelaskan bahwa memfasilitasis siswa dalam pembelajaran terkadang menjadi hal yang disepelekan, salah satunya dalam melakukan kegiatan eksperimen.banyak hal yang menyebabkan ini terjadi daintaranya kurang ketersediaan peralatan laboratorium. Solusi dari permasalahan ini adalah dengan memodifikasi alat dan bahan yang ada disekitar, dengan demikian kreativitas guru sangat dituntun agar dapat terlaksana pembelajaran yang kondusif.

Dalam prosesnya keaktifan siswa merupakan bagian tuntutan dalam implementasi kurkulum 2013. Oleh karena itu, peran guru adalah mendorong, membimbing, dan mengarahkan agar siswa mampu menghasilkan cara-cara atau langkah yang dihasilkan dengan cara mereka sendiri. Tugas seorang guru hanyalah membimbing dan mengarahkan keterampilan komunikasi siswa secara maksimal sedangkan siswa itu sendiri yang mengolah keterampilan komunikasi tersebut.

Budiono dan Rohim (2020:123) menyatakan bahwa guru berperan sebagai fasilitator melalui pembiasaan-pembiasaan ataupun memberikan siswa untuk dapat mengkomunikasikan pendapatnya. Guru memberikan pemodelan atau contoh secara langsung bagaimana menyampaikan informasi dengan baik, jelas dan mudah dipahami. Guru juga berperan sebagai motivator dengan cara memebrikan perhatian lebih bagi siswa yang cenderung pasif di kelas sehingga berani tampil untuk mau menyampaikan pendapatnya. Terlepas dari apa yang disampaikan oleh siswa tepat atau tidak guru juga harus tetap memberikan penguatan dan apresiasi.

\section{Kondisi Kemampuan Practical Skills Siswa setelah diberikan Perlakuan (postest)}

Kemampuan practical skills Siswa setelah diberikan Perlakuan (postest) tedapat peningkatan masing-masing indikator. Dari hasil postest yang dilakukan di dapat bahwa kemampuan practical skills siswa 88,19 dengan kategori sangat tinggi. Hasil ini didukung oleh pendapat Utari, dkk (2013:69) yang menjelaskan bahwa beberapa alasan penggunaan learning cycle yakni mampu memfasilitasi siswa terutama dalam pemecahan masalah, siswa dapat belajar dari pengalamannya, sehingga mampu menerapkan konsep tertentu.

Indikator practical skills yang diamati meliputi Procedural and manipulative skills (keterampilan proseduran dan manipulatif), Observational Skills (keterampilan observasi), Drawing skills (keterampilan menggambar), Reporting and Interpretative 
skills (keterampilan melaporkan dan mengintepretasi). Penjabaran dari setiap indikator sebagai berikut.

Procedural and manipulative skills (keterampilan prosedural dan manipulatif) yang terlihat pada proses pembelajaran meliputi keterampilan dalam menggunakan alat dan bahan serta melakukan percobaan. Dapat terlihat bahwa dalam proses kegiatan praktikum menggunakan petunjuk prkatikum IPA berbasis learning cycle, tampak siswa terampil dalam melakukan prosedural maupun melakukan kegiatan menirukan penggunaan yang tersedia. Kegaiatan ini menunjukkan bahwa dalam proses praktikum, kemampuan siswa lebih tereksplor jika difasilitasi dengan bahan ajar yang sesuai. Selain itu siswa mampu melakukan percobaan sendiri, menganbil keputusan yang sesuai dengan arahan dan petunjuk dalam petunjuk praktikum. Mutlu dan Temiz (2013:765-776), menjelaskan bahwa banyak hal yang didapat siswa dalam proses penemuan sendiri oleh siswa dalam kegiatan pembelajaran. Siswa akan lebih berpikir menyelesaikan masalah dan mengambil keputusan. Bentuk ini merupakan imbas dari keterampilan berpikir yang terus terasah.

Indikator kedua yang diamati adalah Observational Skills (keterampilan observasi). Pada indikator ini tampak kemampuan siswa dalam mengobservasi terhadap kegiatan praktikum yang telah dilakukan. Melalui pembelajaran siklus (learning cycle) yang telah dibuat anak lebih terarah dalam mengamati/mengobservasi melalui inderanya. Indriyati, dkk (2017:15) menyatakan bahwa dalam kegiatan siswa saat proses mengamati halyang paling utama adalah siwa dapat mengumpulkan hasil pengukuran dan pengamatan fisik. Hasil ini digunakan dalam upaya memahami fonomena yang beragam yang tampak oleh siswa. Sehingga siswa akan mampu mejawab pertanyaan atau mencoba sebuah ide yang baru.

Drawing skills (keterampilan mengambar) dilihat bari kegiatan siswa dalam membuat gambaran baik dalam bentuk grafik, tabel maupun gambar. Keterampilan ini tampak jelas bahwa dengan adanya petunjuk praktikum berbasis learning cycle anak lebih terarah dalam membuat tabel sesuai dengan perintah maupun petunjuk kerja yang ada.

Reporting and Interpretative skills (keterampilan melaporkan dan mengintepretasi). Pada indikator ini tampak bahwa siswa mamapu melaporkan kegiatan yang telah dilakukan. Dalam kegiatan pelaporan siswa mampu menuliskan sesuai dengan format yang telah disediakan dalam petunjuk praktikum yang telah dibuat. Dalam indikator ini guru menjadi fasilitator mengarahkan siswa dalam melaporkan dan memginterpretasi data yang telah didapat.

Berdasarkan uraian indikator dapat disimpulkan bahwa agar tercapainya pembelajaran perlu adanya strategi guru, dalam penelitian ini adalah penggunaan petunjuk praktikum berbasis learning cycle. Hal ini didukung oleh pendapat Budiono dan Ulina (2016:348-349) menyatakan bahwa banyak straegi yang dapat dilakukan guru kepada siswa baik dalam bentuk bimbingan, pengajaran maupun pelatihan. Ketiga bentuk ini pada hakikatnya memberikan siswa bantuan, arahan, motivasi, sehingga siswa mempu mengatasi serta menyelesaikan masalah dan menanggulangi kesulitannya sendiri.

Pada prosesnya, IPA tidak hanya dalam bentuk hafalan, namun lebih kepada bagaimana siswa mampu melakukan penyelidikan sederhana untuk melihat fenomena. Ini berarti bahwa dalam IPA yang mencakup produk, proses, dan sikap ilmiah membutuhkan kegiatan praktikum. Praktikum agar terlaksana dengan baik maka membutuhkan petunjuk praktikum sebagai pedoman. Dalam pelaksanaannya penggunaan petunjuk praktikum mengikuti berbagai langkah tahapan learning 
cycle. Saat proses pelaksanaan siswa dibimbing oleh guru sebagai fasilitator pelaksanaan praktikum.

\section{Pengaruh Petunjuk Praktikum IPA Berbasis Learning Cycle Terhadap Practical Skills Siswa}

Nilai signifikansi uji T pada pretest dan Postest sebesar -7,610 kecil dari nilai alpha $0,05(-7,610<0,05)$ dapat diperoleh kesimpulan bahwa terdapat pengaruh signifikan antara penggunaan petunjuk praktikum IPA berbasis learning cycle terhadap practical skills kelas IV SDN 131/IV Kota Jambi.

Hal ini menujukan siswa harus memiliki practical skills yang menjadi bagian dari kemampuan kognitif yang meliputi berbagai kemampuan dalam melakukan percobaan, yang terdiri dari skills memanipulasai, observasi, menggambar, melaporkan serta menginterpretasi (Pratama dan Rosana, 2016:103). Hastuti, dkk (2018) menjelaskan keempat practical skills adalah keterampilan melaporkan dan menafsirkan. Ini termasuk keterampilan dalam mencatat pengamatan sesuai dengan data yang diperoleh, mengklasifikasikan dan menafsirkan pengamatan, dan membuat kesimpulan yang tepat. Keterampilan dalam mencatat pengamatan diperlukan saat mengumpulkan bukti. Tahap pengumpulan bukti dalam pembelajaran isu sains berbasis inkuiri melibatkan peran aktif siswa dalam mengumpulkan alat dan bahan, mengamati, mengumpulkan data, dan merekam pengamatan. Guru memastikan bahwa siswa mencatat pengamatan mereka dan membimbing mereka untuk mencatat pengamatan sesuai dengan fakta yang ditemukan. Penjatahan waktu bagi siswa untuk mencatat pengamatan juga penting

Penggunaan petunjuk praktikum dalam proses pembelajaran IPA akan membuat kegiatan pembelajaran lebih terstruktur dan terarah. Novita (2020:35) menyatakan bahwa perlu adanya suatu perangkat dalam pencapaian tujuan praktikum yakni pedoman praktikum. Dengan adanya isi dari pedoman tersebut kegiatan praktikum akan lebih terarah, lebih terencana, serta lebih sistematis. Suryaningsih (2017:2544) menyebutkan dalam praktikum adanya pembuktian dari siswa dengan cara mengalami sendiri sesuatu yang mereka pelajari caranya adalah dengan melakukan percobaan.

Practical skill siswa sebelum perlakukan berada pada kategori sedang dengan ratarata 63,19. Adanya perlakukan dengan penggunaan petunjuk praktikum berbasis learning cycle menunjukkan adanya peningkatan practical skill siswa pada kategori tinggi dengan rata-rata 88,19 . Hasil ini menunjukkan bahwa adanya petunjuk praktikum berbasis learning cycle memudahkan siswa dalam membangun pengetahuan serta pengalaman yang didapatkan secara aktif. Pendapat ini didukung oleh Fitriyani (2016:514) yang menjelaskan bahwa tujuan utama model learning cycle adalah agar siswa dengan sendirinya mampu mengkonstrusi sendiri pengetahuan dan mendapatkan pengalaman dari apa yang dipelajari sehingga siswa dapat kesempatan untuk belajar secara aktif, serta belajar dengan cara berkelompok maupun individu. Dengan demikian mampu menguasai berbagai kompetensi yang ingin dicapai. Hartono (2013) menjelaskan bahwa learning cycle akan lebih memungkinkan untuk siswa menjadwalkan dan mengatur berbagai tugas yang diberikan guru. Selain itu memungkinkan siswa untuk merencanakan dalam menghasilkan karya. Oleh karenanya learning cycle memberikan kesempatan siswa membuat karya yang berhubungan dengan sains.

\section{Simpulan}

Berdasarkan hasil penelitian dan pembahasan dapat disimpulkan bahwa terdapat pengaruh signifikan antara penggunaan petunjuk praktikum IPA berbasis learning 
cycle terhadap practical skills kelas IV SDN 131/IV Kota Jambi. Kesimpulan ini didapatkan dari hasil uji T menunjukkan bahwa nilai signifikansi pretest dan Postest sebesar - 7,610 kecil dari nilai alpha 0,05 $(-7,610<0,05)$.

\section{Referensi}

Abdullah, \& Marvira, R. (2014). Analisis Keterampilan Psikomotorik dalam Menggunakan Mikroskop pada Siswa Kelas VII SMP Negeri 8 Banda Aceh. Jesbio, 3(5), 2302-1705.

Afriyanti dan Sumardi, Y. (2012). Penerapan Model Pembelajaran OPEK Fisika pada Materi Suhu dan Kalor dan Pengaruhnya terhadap Practical Skill Siswa SMA. Prosiding SNFA (Seminar Nasional Fisika dan Aplikasinya).

Astutik, S. (2012). Meningkatkan Hasil Belajar Siswa Dengan Model Siklus Belajar (Learning Cycle 5e) Berbasis Eksperimen Pada Pembelajaran Sains Di SDN Patrang I Jember. Jurnal Ilmu Pendidikan Sekolah Dasar, 1 (2), 143-153.

Budiono. H dan Ulina. (2016). Pengaruh Alat Peraga Katrol Sederhana terhadap Hasil Belajar Siswa Kelas V Sekolah Dasar. Jurnal Gentala Pendidikan Dasar, 1(2), 348-368.

Budiono, H dan Rohim, A. (2020). Peran Guru Dalam Mengembangkan Keterampilan Komunikasi (Communication) Siswa Kelas V Sekolah Dasar Negeri Teratai. Jurnal IKA, 1(8), 119-127.

Faizal, C. dan Budiono. H. (2019). Pengembangan Buku Petunjuk Praktikum IPA Berbasis Learning Cycle Bagi Siswa Kelas IV Sekolah Dasar. Jurnal Gentala Pendidikan Dasar (JGPD). 4(2). 166-175.

Fitriyani. S., Sudin., Sujana, A. (2016). Penerapan Model Learning Cycle Pada Materi Sumber Daya Alam Untuk Meningkatkan Hasil Belajar Siswa Kelas IVA SDN I Depok Kecamatan Depok Kabupaten Cirebon. Jurnal Pena Ilmiah, 1(1), 511-520.

Hastuti. P.W., Tiarani. V.A., Nurita. T. 2018. The Influence Of Inquiry-Based Science Issues Learning On Practical Skills Of Junior High School Students In Environmental Pollution Topic. Jurnal Pendidikan IPA Indonesia, 7(2), 232 238.

Handayani. D. (2016). Pengembangan Petunjuk Praktikum Pembelajaran IPA Untuk Meningkatkan Practical Skills Siswa SMP. Artikel E-Journal: Universitas Negeri Yogyakarta.

Indriyanti., Mulyasari, E., Sudarya, Y. (2017). Penerapan Pendekatan Saintifik Untuk Meningkatkan Keterampilan Bertanya Siswa Kelas V Sekolah Dasar. Jurnal Pendidikan Guru Sekolah Dasar, 2(2), 13-25.

Margunayasa, I. G. (2014). Pengaruh Petunjuk Praktikum IPA Bermuatan Perubahan Konseptual Terhadap Peningkatan Pemahaman Konsep IPA Pada Mahasiswa PGSD. JPI (Jurnal Pendidikan Indonesia), 3(1), 248-358

Mutlu dan Temiz. (2013). Science Process Skills of Students Having Field Dependent and Field Independent Cognitive Styles. Academic Journals, 8(11), 765-776. 
Nengsi, Sri. (2016). Pengembangan Penuntun Praktikum Biologi Umum Berbasis Inkuiri Terbimbing Mahasiswa Biologi STKIP Payakumbuh. Jurnal IPTEKS Terapan, 10(47), 2460-5611.

Nisa. U.M. (2017). Meode Praktikum untuk Meningkatkan pemahaman Dan Hasi Belajar Siswa Kelas V MI YPII 1945 Babat pada Materi Zat Tunggak dan Campuran. Proceeding Biology Education Conference, 14(1), 62-68.

Novita , E. (2020). Pengembangan Buku Pedoman Praktikum Berbasis Keterampilan Proses Dasar Sains Kelas IV Sekolah Dasar. Journal Evaluation in Education (JEE), 1(1), 34-41.

Odo.M.I., Adenle. S.O.,Okwori. R.O. (2012). Enhancing Mastery Of Practical Skills In Students Of Vocational And Technical Education Through Activity Based Instruction. Journal of Technical Education and Training (JTET), 4(2), 21-29.

Pratama, S., Rosana, D. (2016). Pengembangan Performance Assessment untuk Mengukur dan Memetakan Practical Skills IPA Siswa pada Guided-PjBL di SMP. Jurnal Inovasi Pendidikan IPA. 2 (1). 100-110.

Sugiyono. (2018). Metode Penelitian Pendidikan Kuantitatif Kualitatif dan R\&D. Bandung: Alfabeta.

Sumiati, \& Asra. (2009). Metode Pembelajaran. Bandung: CV Wacana Prima.

Suryaningsih,Y. (2017). Pembelajaran Berbasis Praktikum sebagai Sarana Siswa untuk Berlatih Menerapkan Keterampilan Proses Sains dalam Materi Biologi," Jurnal Bio Education. 2(2). 2541-2280.

Syamsu, D. F. (2017). Pengembangan Penuntun Praktikum IPA berbasis Inkuiri Terbimbing untuk Siswa SMP Siswa Kelas VII Semester Genap. Jurnal Bionatural, 4(2), 2355-3790.

Utari,S. dkk. (2013). Application of Learning cycle 5e Model Aided Cmaptools-Based Media Prototype to Improve Student Cognitive Learning Outcomes. Applied Physics Research By Canadian Center Of Science And Education, 5(4), 69-79.

Windyariani. S. (2017). Pembelajaran IPA denan Praktikum Berbasis Konteks dan Literasi Sains:Prosefektif Guru SD di Sukabumi/ Jurnal Pendidikan Matematika dan IPA, 8(1), 23-33.

Qarareh, A. O. (2012). The Effect of Using the Learning Cycle Method in Teaching Science on the Educational Achievement of the Sixth Graders. International Journal Education Science, 4(2), 123-132. 